\title{
Artigos
}

Matheus de Araújo Alves ${ }^{1}$

Luiza Cardoso Boaventura Vinhal ${ }^{2}$

\section{O CARÁTER TRANSNACIONAL DA PROTEÇÃO AMBIENTAL}

\author{
THE TRANSNATIONAL CHARACTER OF \\ ENVIRONMENTAL PROTECTION
}

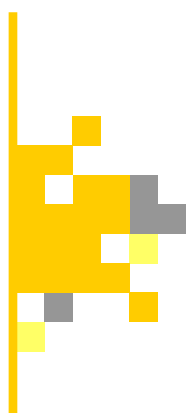

\section{RESUMO:}

As questões relacionadas ao Direito Ambiental no âmbito internacional estão em constante construção e com cada vez mais importância. Diante das variadas catástrofes ambientais, do consumo descontrolado dos recursos naturais e a degradação causada pelas ações do ser humano, a preocupação com o futuro do planeta e da sobrevivência de suas espécies crescem significativamente. Dentre os conceitos que são influenciados por essas questões está o da soberania que, se antes se referia a um poder absoluto e irrestrito de um país, agora só condiz com a realidade quando os Estados agirem de acordo com os limites do Direito Internacional. Por outro lado, deve-se também garantir ao ser humano o direito ao desenvolvimento. Só que, para isso, deve-se atentar às regras de sustentabilidade, pois o desenvolvimento humano só será possível se este for, primeiramente, sustentável.

Palavras-chave: Direito Ambiental; Direito Internacional; Desenvolvimento Sustentável

\section{ABSTRACT:}

Issues related to environmental law at the international level are under constant construction and increasingly important. Faced with various environmental disasters, uncontrolled consumption of natural resources and the degradation caused by human actions, concern for the future of the planet and the survival of its species is growing significantly. Among the concepts that are influenced by these issues is that of sovereignty, which previously referred to the absolute and unrestricted power of a country, now only suits reality when states act within the limits of international law. On the other hand, the human right to development must also be guaranteed. However, for this, one must pay attention to the rules of sustainability, because human development will only be possible if it is primarily sustainable.

Keywords: Environmental Law; International law; Sustainable development

\section{INTRODUÇÃO}

No decorrer do desenvolvimento material das sociedades, o ser humano não dava a devida atenção para os impactos nocivos que suas atividades causavam à natureza, principalmente durante a Revolução Industrial na Europa do século XVIII, onde garantiu-se o surgimento da indústria e a consolidação do processo de formação do capitalismo. Foi somente no início do século XXI que alguns estudiosos passaram a ter um viés preservacionista em relação ao meio ambiente, frente ao crescimento e à expansão desenfreada da economia, em que os países chamados desenvolvidos estavam esgotando os recursos naturais e comprometendo o meio ambiente equilibrado em seus territórios (RAMOS, 2011).

Com o advento da globalização, diversas mudanças foram percebidas no modelo de organização político-social, em que os problemas modernos passaram a ser não mais uma questão nacional e adquiriram, então, um caráter transnacional.

\footnotetext{
${ }_{1}^{1}$ Professor de Direito Constitucional na Faculdade FACISAMG . matheus.aalves@hotmail.com. (iD https://orcid.org/0000-0002-9987-5733

${ }^{2}$ Bacharela em Direito - Centro Universitário de Patos de Minas - UNIPAM. luiza.vinhal@hotmail.com. ID https://orcid.org/0000-0001-8777-7581
} 
Dentre eles, estão a diminuição da camada de ozônio, as mudanças climáticas, a perda de diversidade biológica, as catástrofes naturais como resposta da natureza em relação à ação antrópica e a iminência de escassez de recursos naturais.

Essas questões passaram a integrar a problemática ambiental em uma escala globalizada, tendo seus efeitos adversos sobre o meio ambiente e a qualidade de vida que não respeitam os limites geográficos administrativos, mas atingem toda a comunidade planetária (MORAIS, 2014).

Visando a minimizar tais efeitos, a comunidade internacional se viu obrigada a unir-se para traçar princípios e obrigações próprias à proteção ambiental. Com isso, o poder soberano dos Estados fica obrigado a observar as diretrizes internacionais respeitando os princípios consagrados no Direito Internacional do Meio Ambiente. Nesse sentido, não se pode mais admitir que a soberania estatal seja uma liberdade de os países atuarem independentemente e de forma isolada, à luz de seu próprio interesse, sem que se considere o impacto transnacional de seus atos. Segundo Morais, soberania, hoje, significa cooperação internacional em prol de finalidades comuns, ou seja, o Estado não atua mais de forma isolada, mas como um membro da comunidade e do sistema internacional (MORAIS, 2014).

Além da ressignificação do conceito da soberania, o Direito, feito pela e para a sociedade, também teve de se adaptar à atual conjuntura. Se antes as decisões nacionais competiam apenas à figura do Estado, agora há uma ruptura dos velhos modelos e a necessidade de se abrir espaço aos novos atores, cujo conhecimento técnico, flexibilidade e dinamismo são essenciais à efetividade do Direito Ambiental (FRANCO, 2014). Dessa forma, surgem os pressupostos de que o Direito Ambiental é um direito em constante desenvolvimento e que, por excelência, tem a característica de ser transnacional, difuso e transindividual, pois é através dele que se deve garantir a sobrevivência do planeta, das espécies e, consequentemente, da própria vida humana (PHILIPPI; ZICARELLI, 2013).

O caráter transnacional do direito ambiental se dá porque, sem planeta, evidentemente, não há vida humana. A perpetuação dos recursos naturais para as presentes e futuras gerações exige uma atuação solidária, responsável e urgente em relação à exploração abusiva do meio ambiente. Dessa forma, surge a ideia ou princípio do direito do ser humano ter um meio ambiente ecologicamente equilibrado, cuja essência está na conservação da natureza, com o objetivo de dar continuidade à vida e ao desenvolvimento de todos os seres que habitam o planeta Terra (RAMOS, 2011). Porém, essas ideias não poderiam ficar restritas apenas aos limites territoriais de cada país. Como o habitat do ser humano é único, ou seja, todo o planeta, a proteção do meio ambiente não se restringe às fronteiras desenhadas pelo próprio homem. Essa é a razão de ser dos tratados internacionais firmados entre nações com objetivos e princípios preservacionistas, como o princípio das responsabilidades comuns porém limitadas, o princípio da cooperação, o princípio da prevenção e o da precaução.

\section{DIREITO INTERNACIONAL E MEIO AMBIENTE}

A modernidade e o avanço da globalização trouxeram uma série de mudanças de paradigmas sociais e políticos que contribuíram diretamente para uma nova forma de olhar a questão ambiental, uma vez que a exploração desenfreada dos recursos naturais para o uso da sociedade põe em risco a própria existência do ser humano.

Segundo Gabriel Real Ferrer, o Direito Ambiental surge da necessidade de autodefesa da sociedade em relação aos males que poderiam afetála e que, até então, não vinham sendo percebidos como próprios e ou comuns e, por isso, não despertavam interesses e muito menos reações de ordem jurídica (FERRER, 2002, p. 73).

Junto com o desenvolvimento tecnológico e a busca pelo desenvolvimento de alguns países, o Direito Ambiental caminha paralelamente, como um direito em constante construção e que exige novas reflexões. Dentre as necessárias mudanças de paradigma, está o progressivo abandono do modelo estatal tradicional, sendo substituído por outro que privilegie a interdependência dos Estados 
visando à cooperação e à inclusão de novos atores sociais (FRANCO, 2014). Também é importante ressaltar o desafio de se satisfazer as necessidades sociais do presente, mas sem que isso comprometa a capacidade para que as futuras gerações possam satisfazer suas próprias necessidades.

Accioly e Silva ressaltam que a Comissão Mundial sobre o Meio Ambiente e Desenvolvimento concluiu que muitas das atuais tendências do desenvolvimento resultam em número cada vez maior de pessoas pobres e vulneráveis, além de causarem dano ao meio ambiente, sendo necessário um novo modelo de desenvolvimento que seja capaz de manter o progresso humano não apenas em alguns lugares por alguns anos, mas em todo planeta em um futuro distante (ACCIOLY, SILVA, 2002, p. 53).

Frente à essas tendências que reforçam ainda mais as desigualdades entre os países chamados desenvolvidos e os subdesenvolvidos (ou em desenvolvimento) está a responsabilidade de proteção do meio ambiente que será sempre comum aos Estados, independentemente de seu desenvolvimento. Porém, essa responsabilidade deve ser tratada de forma diferenciada, uma vez que o grau do dano ambiental praticado por cada país e sua capacidade econômica são claramente diferentes (MORAIS, 2014). Para que haja uma efetiva solução dos problemas ambientais, portanto, é preciso que, primeiramente, reconheça-se que a responsabilidade não é individual, mas pertencente a todos os governos, todos os países e todos os cidadãos.

Nesse sentido, é necessário observar que o Direito deve corresponder, igualmente, à nova realidade global, prevendo e propiciando articulação e cooperação entre os diferentes Estados e a sociedade civil, para o desenvolvimento de um Direito Ambiental Internacional que represente, efetivamente, valores comuns.

Segundo Maísa Mendes Morais, os problemas ambientais em cada sociedade ocorrem em função da singularidade da relação entre diferentes contextos, como os fatores econômicos, sociais, políticos, culturais e demográficos que devem ser considerados conjuntamente, pois o desequilíbrio ecológico é fruto da interdependência entre os Estados (MORAIS, 2014).
Em relação às responsabilidades comuns dos Estados, a Declaração do Rio sobre o Meio Ambiente e Desenvolvimento de 1992 traz, no seu Princípio 7, que:

\begin{abstract}
Os Estados devem em um espírito de parceria global, para a conservação, proteção e restauração da saúde e da integridade do ecossistema terrestre. Considerando as distintas contribuição para a degradação ambiental global, os Estados têm responsabilidades comuns porém diferenciadas. Os países desenvolvidos reconhecem a responsabilidade que têm na busca internacional do desenvolvimento sustentável, em vista das pressões exercidas por suas sociedades sobre o meio ambiente global, e das tecnologias e recursos financeiros que controlam (DECLARAÇÃO DO RIO SOBRE O MEIO AMBIENTE E DESENVOLVIMENTO, 1992).
\end{abstract}

A Convenção sobre Diversidade Biológica de 1992 - tratado da Organização das Nações Unidas e um dos mais importantes instrumentos internacionais relacionados ao meio ambiente que fora assinado por mais de 160 países -, adotou o princípio das responsabilidades comuns dos Estados, afirmando que todas as obrigações às partes devem ser implementadas na medida do possível e conforme o caso (CONVENTION ON BIOLOGICAL DIVERSITY, 1992). Com isso, as obrigações poderão variar de Estado para Estado, levando-se em conta sua capacidade técnica, a disponibilidade de seus recursos financeiros e inclusive as variações de ecossistemas.

Ao observar os diversos esforços internacionais com o objetivo de criar uma cooperação entre os diversos países em relação ao meio ambiente, é possível concluir que o Direito Ambiental deve garantir a equivalência de direitos a toda humanidade. Entretanto, primeiro é necessário que essa humanidade esteja viva e, para isso, os recursos naturais não podem se esgotar (PHILIPPI; ZICARELLI, 2013).

\section{SOBERANIA E TRANSNACIONALIDADE}

Soberania é um conceito próprio das ciências política e jurídica, e significa poder de mando de última instância, supremo, exclusivo e não deri- 
vado. É natural que o poder-maior seja exclusivo, pois ele é a gênese do poder, a fonte dos demais poderes ou competências, e não pode ser repartido (RAMOS, 2011).

Segundo Rafael Ramos, o conceito moderno de soberania surgiu no final do século XVI junto com o próprio conceito de Estado, para indicar a plenitude do poder estatal, aquele sujeito único e exclusivo da política, promovendo a unificação e concentração deste com o máximo de unidade e coesão (RAMOS, 2011).

Soberano então é aquele que não enxerga limites formais à sua atuação, nem se submete a nenhum outro poder, pois é incontestável. Suas decisões não podem ser revistas e nem precisam ser confirmadas por outro ente, pois são as decisões últimas e soberanas. Nesse sentido, Paulo Bonavides aduz que a soberania é una e indivisível, indelegável, irrevogável e perpétua (BONAVIDES, 2002, p. 126).

Em contrapartida, o conceito de transnacional traz a ideia de espaço que atravessa o nacional, que perpassa o Estado e está além da concepção soberana deste, acarretando, com isso, uma ausência da dicotomia entre público e privado (STELZER, 2011, p. 25).

Diretamente relacionado com a globalização, a transnacionalidade é um fenômeno no qual as relações humanas, quer sejam políticas, sociais, culturais, religiosas ou comerciais estão ligadas a um transpasse estatal, ou seja, aquilo que vem a cruzar as barreiras ou limites territoriais geográficos impostos por Estados com o objetivo de delimitar seu espaço de atuação (GABRIEL, 2017). Assim, Joana Stelzer ressalta que:

A transnacionalidade insere-se no contexto da globalização e liga-se fortemente à concepção do transpasse estatal. Enquanto globalização remete à ideia de conjunto, de globo, enfim, o mundo sintetizado como único; transnacionalização está atada à referência do Estado permeável, mas tem na figura estatal a referência do ente em declínio. Com efeito, não se trata mais do Estado-territorial, referência elementar surgido após a Paz de Vestefália e que se consolida até o Século XX, viabilizando a emergência do direito internacional sob amparo da ideia soberana (STELZER, 2009).
Quando as ações antrópicas afetam direta ou indiretamente o meio ambiente, não há como se falar em um impacto limitado àquele espaço geográfico do Estado em que este se localiza. A degradação ambiental, a exploração desenfreada dos recursos naturais e os altos índices de poluição e desmatamento geram consequências em toda a sociedade global. Com isso, o conceito de soberania necessita de ser flexibilizado, pois o que está em questão não é um direito nacional, restrito às fronteiras de um Estado, mas um bem jurídico transnacional que, para ser protegido, precisa que sejam assumidas responsabilidades comuns.

O princípio das responsabilidades comuns reconhece as desigualdades entre os Estados, mas não deixa de assegurar que todos os Estados são responsáveis pela conservação do meio ambiente. Nesse sentido, os artigos 6ㅇ e 8ㅇ da Convenção sobre Diversidade Biológica de 1992 preveem que a soberania deve ser exercida na medida da responsabilidade dos Estados e pela conservação e uso sustentável dos seus recursos biológicos (CONVENTION ON BIOLOGICAL DIVERSITY, 1992). Para tanto, é importante ressaltar que o Estado é independente para promover a exploração da diversidade em seu território, mas isso não o exime da responsabilidade de preservar e promover a captação equilibrada dos recursos naturais que se encontram em seu território geográfico.

Segundo MAISA MENDES MORAIS, essa soberania - chamada por alguns autores de soberania responsável -, também reclama dos países ricos um efetivo engajamento com o fim de ajudar os países subdesenvolvidos a superarem seus problemas sociais e ambientais, para que não se caia no velho intervencionismo colonialista das nações ricas, para que estas não se vejam no direito de impor seus padrões e a visão de mundo que vá ao encontro apenas aos seus interesses (MORAIS, 2014).

O Estado, antes de ser soberano, é responsável, e essa responsabilidade não designa apenas o seu espaço de soberania, mas de toda a comunidade humana, igual e fortemente interdependente diante dos perigos ecológicos (BADIE, 2004). O texto da Convenção sobre Diversidade Biológica prevê que, apesar de os Estados serem soberanos, isso 
não os autoriza a explorar de maneira ilimitada seus recursos. Existe, portanto, o reconhecimento não só da soberania, mas também de uma responsabilidade comum.

Essa responsabilidade comum também é chamada de responsabilidade comum diferenciada, pois propicia uma cooperação entre os Estados em busca de soluções para os problemas ambientais globais, sem deixar de reconhecer que alguns Estados possuem maior parcela de responsabilidade na implementação de medidas que equacionem os problemas, considerando que estes contribuíram de forma mais significativa para que houvessem os danos. Esse princípio reconhece a soberania de cada Estado, porém, de forma limitada, pois mesmo este não sendo considerado desenvolvido, é responsável pelas atividades praticadas em seu território. Com isso, além do dever de respeitar a soberania de outros Estados, este deverá garantir os direitos básicos e a dignidade de seus cidadãos (MORAIS, 2014).

Além do reconhecimento da responsabilidade comum, é preciso que os diferentes Estados também assumam a existência de princípios não apenas éticos, mas também jurídicos para se garantir a sobrevivência do planeta. É com a ideia de cooperação e sustentabilidade, por meio de princípios jurídicos como o da solidariedade e da fraternidade, que os países poderão caminhar juntos com as questões humanitárias, o desenvolvimento social, político e econômico sem afrontar o Direito Ambiental transnacional e transindividual (FERRER, 2002).

Para Gabriel Real Ferrer quando se fala em solidariedade, trata-se da ação dispersa convertida em ação coletiva e o privado em público. Em sua faceta ética e moral, o sentimento de solidariedade impulsiona o ser humano a compartilhar aventuras e desventuras entre si, permitindo que se perceba os problemas e emoções uns dos outros. Segundo o autor, a base da sociedade futura está na solidariedade e na empatia (FERRER, 2002).

O princípio da solidariedade também deve vigorar entre as diferentes gerações, postulando o dever de observância dos interesses vindouros, tendo em vista a escassez dos recursos naturais. Para isso, cabe a promoção de princípios como o da prevenção, do desenvolvimento sustentável e do aproveitamento dos recursos naturais, pois o comportamento ecológico e ambientalmente relevante da geração atual impacta e compromete as condições de vida das futuras gerações (CANOTILHO, 2005).

A questão fundamental em relação à tutela do meio ambiente é que, independentemente de localização, país, cultura, religião ou desenvolvimento econômico e social, todos os seres humanos necessitam de um ambiente saudável e equilibrado para sobreviver. A humanidade tem apenas uma casa, que é o mundo que se conhece e se habita. Com isso, cabe não apenas ao indivíduo, mas à toda coletividade tutelar, proteger e usar de forma responsável e sustentável o que a Terra tem para oferecer.

\section{A SOBERANIA NO CONTEXTO DA BI- ODIVERSIDADE}

O princípio da soberania é presente nos mais diversos ordenamentos jurídicos, sendo que, no brasileiro, é um princípio fundamental, mencionado em diversos julgados e considerado nas relações internacionais que o Brasil participa. Entretanto, sua roupagem é um pouco diferente do seu sentido clássico, tendo em vista que, diante do crescimento da interdependência estatal no contexto internacional, surge a chamada soberania responsável (MORAIS, 2014).

Com o objetivo de minimizar os danos ambientais e proteger a qualidade de vida na Terra, os Estados se veem obrigados a cooperar na busca da preservação do meio ambiente. Para encontrarem soluções para problemas de interesses comuns da humanidade, mais de 160 países assinaram a Convenção sobre Diversidade Biológica em 1992 e aceitaram conviver com uma soberania responsável. Nos dias atuais, ter mais ou menos soberania perdeu relevância pois o que importa verdadeiramente é sobreviver em um ambiente equilibrado e sustentável (MORAIS, 2014).

No Brasil, um dos signatários, a questão ambiental passou a ter relevância jurídica principalmente após a Constituição Federal de 1988 
considerar expressamente em seu texto que o direito de viver em um ambiente ecologicamente equilibrado seria um Direito Fundamental.

Para Paulo Affonso Lemes Machado, o limite da soberania está no direito dos outros, e o meio mais adequado para respeitá-lo consiste, especialmente, na proteção do próprio meio ambiente, sem deixar de ressaltar que, não só as gerações presentes têm direito ao desenvolvimento, pois esse direito deve ser exercido de modo a permitir que também sejam atendidas de forma igualitária as necessidades das futuras gerações (MACHADO, 2016).

Com isso, a soberania dos Estados fica, então, limitada ao cumprimento e ao respeito desses interesses, tendo a preocupação relativa aos direitos humanos se constituído em um elemento de sérias limitações ao exercício dessa soberania. Nesse sentido, o Secretário das Nações Unidas reconhece a relativização da soberania quando se trata de bens jurídicos de caráter transnacionais:

A soberania absoluta e exclusiva não é, contudo, mais a mesma, se é que a prática já se igualou à teoria. Aos dirigentes políticos cabe agora compreender esta evolução e encontrar um equilíbrio entre a necessidade de assegurar melhor a direção dos assuntos internos, de uma parte, e as exigências de um mundo cada vez mais interdependente, de outra. $\mathrm{O}$ comércio, as comunicações e as ameaças ao meio ambiente não conhecem fronteiras administrativas; estas não se circunscrevem aos espaços onde os indivíduos vivem, na sua maior parte, suas vidas econômicas, políticas e sociais. A ONU não fechou suas portas. Resta que se cada um dos grupos étnicos, religiosos ou linguísticos pretender um status de Estado, a fragmentação não teria mais limite e a paz, a segurança e o progresso econômico para todos se tornaria cada vez mais difícil de assegurar (VARELLA, 2004).

Dessa forma, é necessário que se dê a devida atenção ao meio ambiente global e a interdependência mundial dos ecossistemas, pois os impactos ambientais podem atingir toda a sociedade global de forma direta ou indireta. Portanto, é preciso que se construam novos valores, como o da responsabilidade, para que os Estados, então, possam ser responsabilizados pela conservação dos bens situados em seu território, tendo em vista o interesse comum da humanidade (MORAIS, 2014).

Para Bertrand Badie, quando se trata de direitos coletivos, a soberania antes absoluta passa a ter uma abrangência limitada e razoável:

A comunidade de cidadãos não se define mais apenas em termos de detenção coletiva de uma potência última, mas como um conjunto de indivíduos obrigados pela natureza das necessidades coletivas conduzidos, por isso, a modificar, transformar, ou mesmo abandonar a concepção soberana da potência que eles pretensamente possuem (BADIE, 2004).

Assim, fica demonstrado que o conceito clássico de soberania absoluta passa a apresentar determinados limites e um caráter de responsabilidade. Na soberania responsável os países colaboram entre si e adotam políticas de sustentabilidade, mas sem que prejuízos sejam causados à territórios vizinhos, que também são passíveis de proteção internacional.

\section{PRINCÍPIO DA COOPERAÇÃO}

Cooperação não significa renúncia da soberania estatal, porém, uma vez signatário de acordos bilaterais ou multilaterais, o Estado passa a ser sujeito das obrigações voluntariamente contraídas. O princípio da cooperação, então, consiste em uma troca de informações, tecnologias, assistência técnica e financeira e conhecimento científico entre os países que, desde 1972, já era prevista na Declaração de Estocolmo, em seu Princípio 24:

Todos os países, grandes e pequenos, devem ocupar-se com espírito e cooperação e em pé de igualdade das questões internacionais relativas à proteção e melhoramento do meio ambiente. É indispensável cooperar para controlar, evitar, reduzir e eliminar eficazmente os efeitos prejudiciais que as atividades que se realizem em qualquer esfera, possam ter para o meio ambiente, mediante acordos multilaterais ou bilaterais, ou por outros meios apropriados, respeitados a soberania e os interesses de todos os estados (DECLARAÇÃO DE ESTOCOLMO, 1972). 
A Convenção sobre Diversidade Biológica de 1992 também adota este princípio, prevendo que cada Estado-Signatário deverá cooperar, na medida do possível, para a conservação e utilização sustentável da biodiversidade. Em seu artigo 18, a Convenção trata da cooperação técnica e científica, na qual as Partes se comprometem a cooperar, independentemente de seu nível de desenvolvimento, com o objetivo de promover a conservação e uso sustentável da biodiversidade, o desenvolvimento e a utilização de novas tecnologias (MORAIS, 2014).

No âmbito da política global, diversas iniciativas inspiradas na Convenção sobre Diversidade Biológica já foram tomadas, sendo estas resultantes de relações internacionais entre diversos atores como ONGs, agências de cooperação, pesquisadores, cientistas e órgãos governamentais. Segundo Morais, a maior parte dessas iniciativas envolvem recursos técnicos, científicos, tecnológicos e ou financeiros de países desenvolvidos e agências multilaterais (MORAIS, 2014).

\section{PRINCÍPIO DA PREVENÇÃO E DA PRECAUÇÃO}

O princípio da prevenção baseia-se na necessidade de se avaliar previamente as possíveis consequências, para evitar efeitos prejudiciais à saúde humana e ao meio ambiente ainda na sua origem. A prevenção incide sobre impactos ambientais que já são conhecidos. Para o Jean Marc Lavieille, a prevenção "é uma chance para a sobrevivência" (VARELLA, 2004).

De acordo com Édis Milaré, os objetivos do Direito Ambiental são preventivos. Como os danos ambientais são de difícil reparação, esta geralmente se torna incerta e excessivamente onerosa, fazendo com que a prevenção seja a melhor, senão a única solução (MILARÉ, 2004).

Por outro lado, o princípio da precaução fundamenta-se nos danos incertos que uma determinada atividade pode causar. Parte da doutrina como Barros-Platiu, afirma que o princípio da precaução complementa o da prevenção.

A sociedade atual, também chamada de So- ciedade de Risco pelo sociólogo alemão Ulrich Beck (2017), é caracterizada pela constante produção de riscos globais, que exigem por parte do Direito, decisões baseadas na expectativa de um dano futuro, para que se possa agir de maneira antecipada. Com isso, o Direito passa a ser visto não só como um elemento corretivo, mas também como um instrumento para gestão de risco e prevenção de dano ambiental (MORAIS, 2014). Nesse sentido, a Declaração do Rio sobre o Meio Ambiente e Desenvolvimento de 1992, em seu artigo 15, dispõe que:

\begin{abstract}
De modo a proteger o meio ambiente, o princípio da precaução deve ser amplamente observado pelos Estados, de acordo com suas capacidades. Quando houver ameaça de danos sérios ou irreversíveis, a ausência de absoluta certeza científica não deve ser utilizada como razão para postergar medidas eficazes e economicamente viáveis para prevenir a degradação ambiental (MORAIS, 2014).
\end{abstract}

A Convenção sobre Diversidade Biológica de 1992 não prevê explicitamente o princípio da precaução, mas este pode ser percebido de forma implícita em seu preâmbulo quando traz que: "observando também que quando exista ameaça de sensível redução ou perda de diversidade biológica, a falta de plena certeza científica não deve ser usada como razão para postergar medidas para evitar ou minimizar essa ameaça" (CONVENTION ON BIOLOGICAL DIVERSITY, 1992).

\section{PRINCÍPIO DA PROTEÇ̃̃O DO DIREI- TO AO DESENVOLVIMENTO HUMANO}

No âmbito do Direito Ambiental Internacional, ainda não foi possível se implementar uma norma transnacional única e atualizada, o que contribuiria significativamente para a proteção do meio ambiente. Essa é uma das maiores dificuldades de se estabelecer proteção ambiental, porque cada país tem seu aspecto cultural, político, social e econômico próprios e não há uma legislação internacional para o meio ambiente que possa estabelecer qualquer obrigação ambiental, nem pena a seu descumprimento. Philippi e Zica- 
relli ressaltam que, no máximo o que se estabelece são mecanismos políticos, diplomáticos ou embargos comerciais, que já não se mostram mais suficientes (PHILIPPI; ZICARELLI, 2013).

A degradação ambiental, o aquecimento global e a iminência do esgotamento dos recursos naturais são exemplos de questões que trazem consigo uma necessidade imediata de atuação para serem contidos, o que justifica que sejam construídos espaços transnacionais de atuação normativa. Isso posto, de nada adiantaria, por exemplo, uma nação cuidar de forma individual de seu território e ter uma excelente legislação e consciência ecológica em seu meio social, se o país vizinho explora o meio ambiente de forma irracional e compromete o ecossistema como um todo.

É, portanto, necessário e urgente para a sobrevivência da vida na Terra, contribuir para a criação e a integração de um Direito Ambiental Transnacional e propiciar a consagração do meio ambiente equilibrado como um valor coletivo e que condiciona a própria vida. Proteger esse valor coletivo é mais do que resguardar a geração presente, é também indispensável para a sobrevivência das gerações futuras e para o desenvolvimento humano, que só se dará se realizado de forma sustentável (PHILIPPI; ZICARELLI, 2013).

Fernando Almeida nesse sentido afirma que as atividades humanas estão utilizando os serviços ambientais em um ritmo que já não é mais garantida a capacidade dos ecossistemas satisfazerem às necessidades das futuras gerações. A demanda por água e alimentos para atender a uma população crescente representa um custo além do suportável e que, se mantida essa tendência, a infraestrutura natural se fragilizará ainda mais nas próximas décadas (ALMEIDA, 2007, p. 15).

De acordo com Accioly e Silva, a Comissão Mundial sobre o Meio Ambiente e Desenvolvimento conclui que muitas das tendências do desenvolvimento além de causarem prejuízos ao meio ambiente, também resultam em um número cada vez maior de pessoas pobres e vulneráveis. Para a Comissão, o progresso humano não deve ser mantido apenas em algumas regiões e por alguns anos, mas em todo o mundo até um futuro longínquo, o que só acontecerá por meio do desenvolvimento sustentável (ACCIOLY; SILVA, 2002, p. 49). Porém, é importante ressaltar que desenvolvimento sustentável não é apenas aquele ecologicamente sustentável, mas o que visa igualmente às dimensões sociais, econômicas, políticas e culturais.

Se o desenvolvimento é um dos direitos fundamentais do ser humano, aplicado de forma inconsciente e sem critérios, acarretará em destruição do que resta do meio ambiente. Para Patricia Philippi e Leonardo Zicarelli, essa é a prova de que se faz urgente um novo pensar a respeito do Direito Ambiental, que precisa ter um alcance global e um pensar que abandone a postura unilateral, pois todos precisam estar dispostos a dar sua colaboração, visando à continuidade do planeta e de suas espécies, sobretudo, a espécie humana (PHILIPPI; ZICARELLI, 2013).

Todo e qualquer Estado possui direito ao desenvolvimento e, sem ele, a natureza também é seriamente afetada. Porém, esse desenvolvimento necessita de sustentabilidade, solidariedade, fraternidade e responsabilidade. Somente com respeito a esses princípios e de forma colaborativa é que se poderá alcançar a sobrevivência na Terra. E essa é a casa de todos, não só de alguns.

\section{CONCLUSÃO}

Como é possível identificar no presente trabalho, as questões relacionadas ao Direito Ambiental no âmbito internacional estão em constante construção e com cada vez mais importância. Diante das variadas catástrofes ambientais, do consumo descontrolado dos recursos naturais e a degradação causada pelas ações do ser humano, a preocupação com o futuro do planeta e da sobrevivência de suas espécies crescem significativamente.

Dentre os conceitos que são influenciados por essas questões está o da soberania que, se antes se referia a um poder absoluto e irrestrito de um país, agora só condiz com a realidade quando os Estados agirem de acordo com os limites do Di- 
reito Internacional. Os compromissos internacionais firmados pelos países não anulam sua soberania, mas retiram desses sua característica absoluta. Há, portanto, uma relativização do conceito de soberania que passa a ter um caráter responsável, perante assuntos relacionados aos direitos transnacionais como o ambiental.

Por outro lado, deve-se também garantir ao ser humano o direito ao desenvolvimento. Só que, para isso, deve-se atentar às regras de sustentabilidade, pois o desenvolvimento humano só será possível se este for, primeiramente, sustentável. A Terra é um organismo vivo e integrado que depende, para sua proteção, de ações colaborativas e de um uso responsável de seus recursos, independentemente de limites territoriais.

Assim, conclui-se que o Direito Ambiental não deve se limitar às fronteiras geográficas, sociais ou políticas, mas ser um bem de toda humanidade que é a responsável pela sua devida proteção. Tem-se, portanto, um direito de urgência, preventivo, solidário, transnacional e difuso, que deve ser encarado sempre de forma coletiva, sob pena de extinção da própria vida na Terra.

\section{REFERÊNCIAS}

ACCIOLY, Hildebrando; SILVA, Geraldo Eulalio do Nascimento. Manual de Direito Internacional

Público. 15.ed. São Paulo: Saraiva, 2002.

ALMEIDA, Fernando. Os desafios da sustentabilidade. Rio de Janeiro: Elsevier, 2007.

\section{BADIE, Bertrand. Da soberania à competência do}

Estado. In: SMOUTS, Marie-Claude. As novas relações internacionais: práticas e teorias. Brasília. UNB. 2004.

CANOTILHO, José Joaquim Gomes. 0 direito ao ambiente como direito subjectivo. In: A tutela jurídica do meio ambiente: presente e futuro. Boletim da Faculdade de Direito da Universidade de Coimbra - Stvdia Ivridica 81, Colloquia 13. Coimbra: Coimbra Editora, 2005.

\section{CONVENTION ON BIOLOGICAL DIVERSITY. 1992.}

Disponível em: https://www.cbd.int. Acesso em: 5 nov. 2019.

FERRER, Gabriel Real. La construcción del Derecho Ambiental. In: Revista Arazandi de Derecho Ambiental. Pamplona (España), n. 1, v.1, 2002

FRANCO, Carla Daniela Kons. O papel das organizações não governamentais na proteção do direito fundamental ao meio ambiente ecologicamente equilibrado. 2014. Disponível em: https:// jus.com.br/artigos/30519/o-papel-das-organiza coes-nao-governamentais-na-protecao-do-direitofundamental-ao-meio-ambiente-ecologicamenteequilibrado\#. Acesso em: 5 nov. 2019.

GABRIEL, Luiz Felipe Camelo; et al. O fenômeno da transnacionalidade na inserção de um sistema de comércio justo em uma sociedade em rede. [S. I.], 2017. Disponível em: https://jus.com.br/artigos/ 61590/o-fenomeno-da-transnacionalidade-na-in sercao-de-um-sistema-de-comercio-justo-em-uma -sociedade-em-rede. Acesso em: 5 nov. 2019.

MACHADO, Paulo Affonso Leme. Direito ambiental brasileiro. 24. ed., rev., ampl., e atual. São Paulo: Malheiros, 2016.

MILARÉ, Edis. Direito do Meio Ambiente: doutrina, jurisprudência, glossário. 3. ed. ver., atual. e ampl. São Paulo: Revista dos Tribunais, 2004.

MORAIS, Maisa Mendes. A Convenção sobre a Diversidade Biológica e a soberania dos Estados. [S. I.], 2014. Disponível em: https://jus.com.br/arti gos/29877/a-convencao-sobre-a-diversidade-bio logica-e-a-soberania-dos-estados. Acesso em: 5 nov. 2019.

PHILIPPI, Patricia Pasqualini; ZICARELLI, Leonardo. O direito transnacional ambiental e a proteção do direito ao desenvolvimento humano. Revista Eletrônica Direito e Política, Programa de Pós- Graduação Stricto Sensu em Ciência Jurídica da UNIVALI, Itajaí, v.8, n.3, 30 quadrimestre de 2013. Disponível em: www.univa li.br/direitoepolitica - ISSN 1980-7791. 
RAMOS, Rafael Antonio Braga. Soberania e o Direito Internacional do Meio Ambiente. [S. I.], 2011. Disponível em: http://

momentum.emnuvens.com.br/momentum/issue/ view/n9/showToc. Acesso em: 5 nov. 2019.

STELZER, Joana. O Fenônemo da Transnacionalização da Dimensão Jurídica. In: CRUZ, Paulo Márcio; STELZER, Joana (org.). Direito e Transnacionalidade. Curitiba: Juruá, 2011.
STELZER, Joana. Transnacionalização: o emergente cenário do comércio mundial. In: Revista Portuária, Itajaí, Julho de 2009. Disponível em: http:// www.revistaportuaria.com.br/colunas/391. Acesso em: 5 nov. 2019.

VARELLA, Marcelo Dias. Direito internacional econômico ambiental. Belo Horizonte: Del Rey, 2004. 